\title{
An imperfect production inventory model with setup cost reduction and carbon emission for an integrated supply chain
}

\author{
Prerna Gautam and Aditi Khanna*
}

Department of Operational Research, Faculty of Mathematical Sciences, University of Delhi, Delhi 110007, India

\begin{tabular}{l}
\hline C H R O N I C L E \\
\hline Article history: \\
Received March 2, 2017 \\
Received in revised format \\
October 10, 2017 \\
Accepted November 222017 \\
Available online \\
November 222017 \\
\hline Keywords: \\
Integrated model \\
Imperfect-production \\
Setup cost reduction \\
Shortages \\
Carbon-emission \\
Warranty
\end{tabular}

\section{Introduction}

Efficient management of production and inventory decisions is the backbone for maintaining smooth drive of the supply-chain system. The fundamental of any inventory modeling revolves around the products. Therefore, it becomes essential to cogitate about products practicality in the supply chain structure. Thus, it is quite unrealistic to consider the products to be of perfect quality, as due to numerous reasons (faulty production process, mishandling during transportation etc.) the end product may not withstand with the quality standards set by the manufacturer. Consequently, the firm has to deal with imperfect quality items. The researchers who initiated working in this area were Porteus (1986), Rosenblatt and Lee (1986), Lee and Rosenblatt (1987), Kim and Hong (1999), Later, Ben-Daya and Hariga (2000), Salameh and Jaber (2000), Cardenas Barron (2000), Yeh et al. (2000), Huang (2002), Chung and Hou (2003), Ben-Daya and Rahim (2003), Huang (2004), Ha and Kim (1997), Hsieh and Lee (2005), Chen and Lo (2006), Ben-Daya and Al-Nassar (2008), Sana (2011), Lu et al. (2016) and many others came up with the pioneer research in the field of imperfect quality items.

\footnotetext{
* Corresponding author. Tel. and Fax: 91-11-27666672

E-mail address: dr.aditikhanna.or@gmail.com (A. Khanna)

C 2018 Growing Science Ltd. All rights reserved. doi: $10.5267 /$ j.uscm.2017.11.003 
To achieve sustainability, spherical growth is required rather than individual growth. The success of a single entity will not pay in the long run until the overall supply chain system is benefitted. Thus, the act of working in collaboration is the best supply chain strategy for today's business enterprises. Accordingly, the emphasis is on optimizing the inventory and production decisions mutually. The area of integrated inventory modeling is explored by plenty of researchers. The preliminary research in this area was carried out by Goyal (1977), in which he presented a problem of single vendor and single customer. Afterwards, Banerjee (1986), Goyal (1988), Goyal and Gupta (1989), Aderohunmu et al. (1995), Lu (1995), Ha and Kim (1997), Viswanathan (1988), Hill (1997, 1999), Hoque and Goyal (2000), Goyal and Szendrovits (1986), Goyal and Nebebe (2000), Yang and Wee (2000), Wu and Ouyang (2003), Chung (2008), Shah and Shah (2012),Hsu and Hsu (2012, 2013) and several others carried forward the research work in the field of integrated modeling and presented the decision makers with integrated policies, that can be adopted to maximize benefits for all the participating players.

Further, in the vendor-buyer inventory models, it is tacitly presumed that the vendor handles the manufacturing department and the buyer governs the sales department. Also, the buyer places the orders and the vendor needs to fulfill the request. The flow of products between the two players is done at some transportation cost which is incurred by either the vendor or the buyer. During transportation, carbon-emissions take place which is the foremost reason behind environmental degradation. The organizations nowadays operate in a global fishbowl, so, any shortcomings are on a full display. Thus, to maintain the goodwill it is mandatory to look towards sustainable business which involves the consideration of carbon-emissions. The researchers who contributed in this area are Shi and Meier (2012), Shi et al. (2012), Zhang et al. (2013), Hammami et al. (2015), Tang et al. (2015), Sarkar et al. (2016), Tang et al. (2016), Cheng et al. (2016). These researchers considered the carbon-emissions in their inventory modeling.

While talking about the manufacturing sector it is crucial to building a reliable setup for the smooth operation of the manufacturing process. Also, investment in the setup process is quite beneficial as it aids in minimizing the costs for the subsequent cycles. Recently, researchers incorporated scenario of investment in setup costs which aids in cost reduction at manufacturing end (Denizel et al., 1997; Diaby, 2000; Nyea et al., 2001; Freimer et al., 2006; Annadurai \& Uthayakumar, 2010; Huang et al., 2011; Sarkar \& Majumder, 2013; Sarkar et al., 2015; Sarkar et al., 2016). Moreover, the uncertainty in supply and demand leads to shortages which is a real phenomenon to incorporate in inventory and supply chain modeling. The presence of imperfect quality items may result in shortages as a fraction of on-hand inventory is salvaged/removed from the stock. Thus, it becomes pragmatic to include shortages. Planned backorders are usually adopted by numerous industries viz. furniture showrooms, automobile, and mobile industries, etc. Researchers who incorporated shortages in their modeling were, Wee et al. (2007), Eroglu and Ozdemir (2007), Chang and Ho (2010), Cardenas-Barron (2009), Hsu and Hsu (2012, 2013), Sarkar and Moon (2014), Khanna et al. (2016), etc.

The present paper highlights the significance of collaborative strategies in today's competition inherited marketing world. A supply chain problem with a single vendor and buyer is discussed. An imperfect production scenario at the vendor's end is considered which ends up producing defectives. The defectives are secluded with the help of a screening process employed by the buyer so as to satisfy the end demand with good quality products. In order to manage the defectives efficiently, the buyer returns it to the vendor for further treatment which incurs a warranty cost. Climate degradation is a key issue in sustainability. It may lead to dangerous increases in temperature and sea level, flooding etc. Scientists all over the world declare GHG as the main malefactor for environmental change and this compels the government to set various emission norms. "Carbon" is often used as shorthand for greenhouse gases (GHGs) as it is regarded as the main element for measuring GHG. A sound environment-friendly policy of a firm can earn it an extremely good image which will ultimately elevate sales and profitability. Thus, the paper incorporates the carbon-emissions costs while transportation so as to achieve sustainability. A discrete investment in setup cost is also considered so as to reduce the overall cost of manufacturing for subsequent production cycles. Shortages are considered with complete backlogging 
at the side of the buyer. Accounting to the above-discussed scenario the present paper proposes an inventory framework under integrated environment to address a faulty manufacturing process with setup cost reductions, carbon-emissions, and shortages. Moreover, two scenarios are discussed viz. the individual decision-making strategy and the integrated strategy. The findings are compared with both the strategies and it is further suggested that the integrated model is superior by showing appropriate cost reductions. The numerical analysis is given along with the detailed sensitivity analysis to demonstrate and support the model features. The present model is extensively relevant for production firms like leather, plastic, electronics etc.

The remaining paper is presented as: Section 2 gives the notations, Section 3 lists the assumptions on which the present model is developed, Section 4 describes the problem and gives mathematical model, Section 5 gives model optimization and provides the solution procedure, Section 6 and 7 establishes the validity and robustness by giving numerical example and model sensitivity, and the last section summarizes the paper by giving conclusion and scope for future research.

\section{Notations}

$\begin{array}{ll}\lambda & \text { Rate of demand (unit/year) } \\ \psi & \text { Rate of production (unit/year) } \\ o & \text { Defective percentage in the ordered lot } \\ Q & \text { Order quantity } \\ B & \text { Backordering quantity } \\ N & \text { Number of freights } \\ O_{B} & \text { Cost of ordering (\$/order) } \\ H_{B} & \text { Cost of holding inventory at buyer's end (\$/unit/year) } \\ H_{V} & \text { Cost of holding inventory at vendor's end (\$/unit/year) } \\ S & \text { Cost of screening at buyer's end (\$/unit) } \\ C_{F} & \text { Fixed cost of carbon-emissions at vendor's end }(\$ / \text { transport) } \\ C_{V} & \text { Variable cost of carbon-emissions at vendor's end }(\$ / \text { unit) } \\ T_{F} & \text { Fixed cost of transportation at vendor's end (\$/transport) } \\ T_{V} & \text { Variable cost of transportation at vendor's end (\$/unit) } \\ S_{0} & \text { Initial cost of setup (\$/setup) } \\ S_{v} & \text { Setup cost (vendor)after investment (\$/setup) } \\ C_{B} & \text { Cost of backordering at buyer's end (\$/order) } \\ W_{V} & \text { Unit warranty cost (per defective item at buyer) }\end{array}$

\section{Assumptions}

i. Demand and production rates are considered to be known and constant. Some of the references of such type are: Khanna et al. (2016b), Chung et al. (2002), Choi et al. (2008), Wee et al. (2014), Sarkar and Saren (2015), Kaliraman et al. (2016) etc.

ii. Known and constant lead time is considered.

iii. Lot size $Q$ carries defectives. The defective rate $\hat{o}$ follows the $\operatorname{pdf} f(\delta)$. Moreover, it is presumed that $E[\delta]<1-\lambda / \psi$, so as to safeguard the manufacturing capacity to be enough to fulfill the annual demand of the buyer.

iv. Single-vendor, single buyer and a single type of product is considered. 
v. Shortages are fully backlogged.

vi. Fixed and variable costs of carbon-emissions are considered at the vendor's end.

vii. The lot undergo a complete screening test prior to the commencement of each cycle time $T$. Entire lot of defectives are reverted to the vendor, upon reception of the subsequent delivery. In this case fixed and variable parts of transportation costs are considered. A warranty cost $W_{V}$ is incurred by the vendor for an imperfect item. The vendor sells out the defectives on a lesser amount in some subordinate market. The inspection duration is reckoned as lead-time for supply.

viii. A discrete investment $I$ is incorporated for minimizing the setup cost which is defined as $S_{v}(\xi)=S_{0} e^{-k \xi}$, where $k$ is a known parameter. It has been established that increase in investment amount lowers the resultant cost of setup.

\section{Problem Definition and Mathematical Modeling}

\subsection{Problem Definition}

The present paper attempts to bridge the research gap within an integrated supply chain system by presenting a sustainable framework for the problem of vendor and buyer. A yearly demand of $\lambda$ units is considered at buyer. The buyer orders regularly in fixed batches of size $Q_{\text {prod }}$. The vendor takes the responsibility to cater the orders by manufacturing the products in batches (of size $Q_{\text {prod }}$ ), and plans to ship the quantities to the buyer in $N$ number of consignments each of $Q$ units. Since the production process is presumed as imperfect, accordingly the shipments contain items of imperfect quality, to deal with it the buyer employs an inspection process and revert the defectives to vendor. The vendor incurs warranty cost for defectives, in this manner; end demand of the customer is satisfied with perfect quality items. It has been further presumed that shortages at buyer is allowed and are assumed to be completely backlogged. The transportation process between the two players is governed by the vendor for which a fixed as well as a variable component of shipments and carbon-emissions is taken into account. The prime goal lies in minimizing the costs acquired by the two players by jointly optimizing the number of shipments, the size of shipments, back-ordering quantity and investment in setup cost. Also, to achieve sustainability by showing appropriate cost reductions in case of the integrated model while comparing with the independent model.

\subsection{Vendor's Viewpoint}

The Fig. 1(a) represents the scenario of the vendor over time and Fig. 1(b) represents the inventory carrying cost per cycle. The components of vendor total cost comprises of costs of setup, investment in setup, inventory carrying, transportation and carbon-emission which are evaluated below:

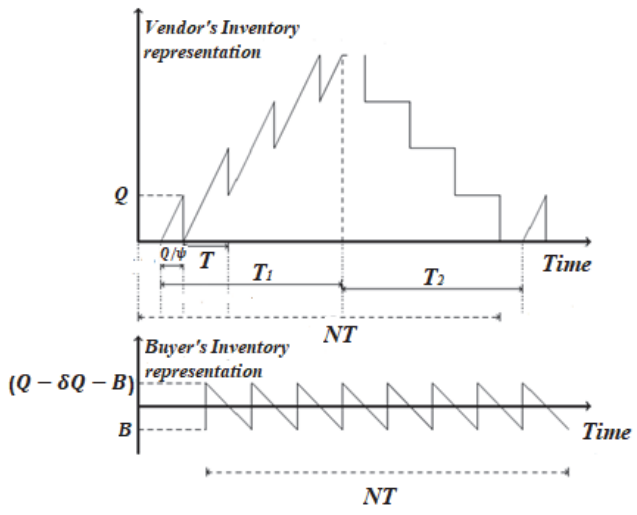

1 (a)

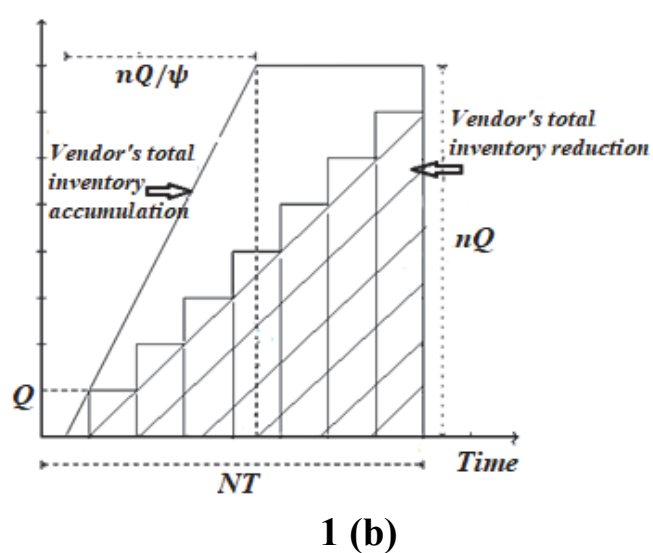

1 (b)

Fig. 1. Inventory representation over time for vendor 
The model considers investment in setup cost so the setup cost is given as:

Setup cost $S_{v}(\xi)=S_{0} e^{-k \xi}$,

Investment in setup cost $=\xi$,

The cost of holding inventory in case of vendor is obtained [Goyal et al (2003) and Huang (2004)] by subtracting the shaded area from the bold area (see Fig. 1 (b)),

Holding cost $=H_{V}\{$ BoldArea - ShadedArea $\}$

$$
\begin{aligned}
& =H_{V}\left\{\left[N Q\left(\frac{Q}{\psi}+(N-1) T\right)-\frac{N Q(N Q / \psi)}{2}\right]-T[Q+2 Q+\ldots+(N-1) Q]\right\} \\
& =H_{V}\left\{\left[N Q\left(\frac{Q}{\psi}+(N-1) \frac{Q(1-\delta)}{\lambda}\right)-\frac{n Q(n Q / \psi)}{2}\right]-\frac{Q(1-\delta)}{\lambda}[Q+2 Q+\ldots+(N-1) Q]\right\} \\
& =H_{V}\left\{\frac{N Q^{2}}{\psi}-\frac{N^{2} Q^{2}}{2 \psi}+\frac{N(N-1) Q^{2}(1-\delta)}{2 \lambda}\right\},
\end{aligned}
$$

Since the vendor is responsible for shipping the products. Also, the buyer sends back the defectives to the vendor, in view of this there are fixed and variable components associated with the transportation cost which is defined as follows:

Transportation cost $=N T_{F}+T_{V} N Q E[\delta]$,

While shipping the products from the vendor to the buyer or vice-versa, fixed and variable costs of carbon-emissions is incurred this is given as:

Cost of Carbon Emission $=N C_{F}+C_{V} N Q E[\delta]$,

Warranty Cost $=W_{V} N Q E[\delta]$

Thus, total cost per cycle for vendor is:

$$
\begin{aligned}
& T C_{V}(N, Q, \xi)=S_{0} e^{-k \xi}+\xi+H_{V}\left\{\frac{N Q^{2}}{\psi}-\frac{N^{2} Q^{2}}{2 \psi}+\frac{N(N-1) Q^{2}(1-\delta)}{2 \lambda}\right\}+N T_{F}+T_{V} N Q E[\delta]+N C_{F}+ \\
& C_{V} N Q E[\delta]+W_{V} N Q E[\delta]
\end{aligned}
$$

\subsection{Buyer's Viewpoint}

The buyer's situation is represented in Figure 2. The buyer's total cost is a sum of the costs of ordering, holding, screening and backordering. The cost components are evaluated as follows:

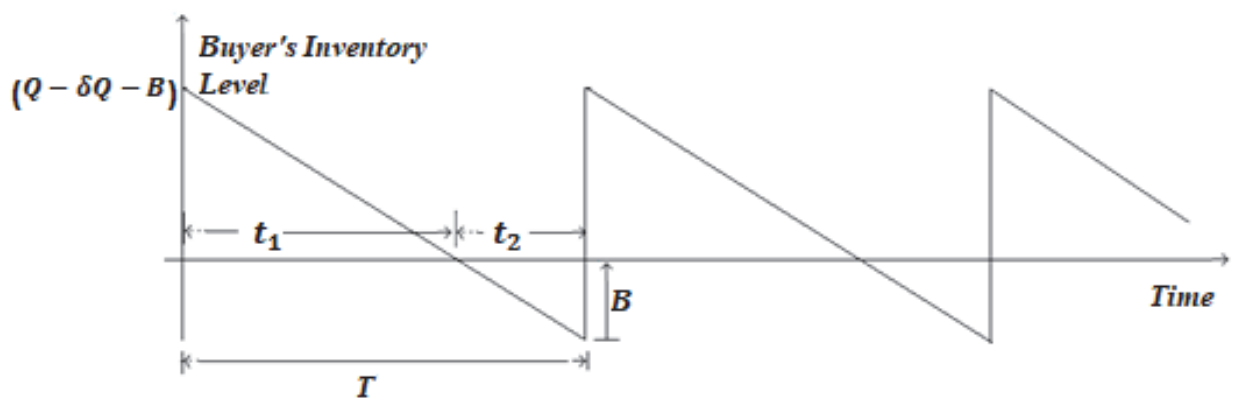

Fig. 2. Inventory representation over time for the buyer 
Orders are placed by the buyer with fixed ordering cost given as:

$$
\text { Ordering Cost }=O_{B}
$$

Since, the received lot contains both perfect as well as imperfect items it is therefore necessary to conduct screening, so the following cost of screening is incurred by the buyer:

$$
\text { Screening Cost }=S N Q
$$

Considering the perfect quality articles the average inventory is $\frac{1}{2}\{Q(1-\delta)-B\}$. The average inventory level of the defective item is $\delta Q$ and these are reverted to the vendor on accepting the subsequent lot. Thus, the time points are defined as (see Fig. 1):

The depletion of positive inventory level is governed by the following time point: $t_{1}=\frac{(Q-\delta Q-B)}{\lambda}$, and

The total cycle time is defined as: $T=t_{1}+t_{2}$,

$T=\frac{Q(1-\delta)}{\lambda}$ so, the total inventory carrying cost of the buyer is given as:

Holding Cost $=H_{B} N\left\{\frac{1}{2} \frac{(Q-\delta Q-B)^{2}}{\lambda}+\frac{Q^{2} \delta(1-\delta)}{\lambda}\right\}$

The shortage time is defined as: $t_{2}=\frac{B}{\lambda}$, so the backordering cost of the buyer can be given as:

Backordering Cost $=\frac{N C_{B} B^{2}}{2 \lambda}$

The total cost of buyer is incurred due to placing order, holding inventory, backorders and screening process. Thus, the buyer's total cost per cycle is:

$$
T C_{B}(N, Q, B)=O_{B}+S N Q+H_{B} N\left\{\frac{1}{2} \frac{(Q-\delta Q-B)^{2}}{\lambda}+\frac{Q^{2} \delta(1-\delta)}{\lambda}\right\}+C_{B} N \frac{1}{2} \frac{B^{2}}{\lambda}
$$

\subsection{Joint Perspective of vendor and buyer}

The joint total cost is given as:

$$
\begin{aligned}
& T C_{I}(N, Q, B, \xi)=T C_{B}(N, Q, B)+T C_{V}(N, Q, \xi) \\
& T C_{I}(N, Q, B, \xi)=O_{B}+S N Q+S_{0} e^{-k \xi}+\xi+H_{B} N\left\{\frac{1}{2} \frac{(Q-\delta Q-B)^{2}}{D}+\frac{Q^{2} \delta(1-\delta)}{\lambda}\right\}+C_{B} N \frac{1}{2} \frac{B^{2}}{\lambda}+ \\
& H_{V}\left\{\frac{N Q^{2}}{\psi}-\frac{N^{2} Q^{2}}{2 \psi}+\frac{N(N-1) Q^{2}(1-\delta)}{2 \lambda}\right\}+N T_{F}+T_{V} N Q E[\delta]+N C_{F}+C_{V} E[\delta] N Q+W_{V} N Q E[\delta] \\
& \text { The cycle length is given as } E\left[T_{c y c}\right]=\frac{N Q(1-E[\delta])}{\lambda} .
\end{aligned}
$$

By implementing the renewal reward theorem, the joint total expected cost is: 


$$
\begin{aligned}
& \mathrm{ETC}(N, Q, B, \xi)=\frac{\mathrm{E} T C_{I}(N, Q, B, \xi)}{\mathrm{E}\left[T_{c y c}\right]}=\frac{O_{B} \lambda}{N Q(1-\mathrm{E}[\delta])}+\frac{S N Q \lambda}{N Q(1-\mathrm{E}[\delta])}+\frac{S_{0} \lambda e^{-k \xi}}{N Q(1-\mathrm{E}[\delta])}+\frac{\xi \lambda}{N Q(1-\mathrm{E}[\delta])}+ \\
& H_{B}\left\{\frac{1}{2}\left(\frac{E\left[(1-\delta)^{2}\right]}{(1-E[\delta])}-2 B+\frac{B^{2}}{Q(1-E[\delta])}\right)+\frac{Q\left(E[\delta]-E\left[\delta^{2}\right]\right)}{(1-E[\delta])}\right\}+C_{B} N \frac{1}{2} \frac{B^{2} \lambda}{\lambda n Q(1-E[\delta])}+ \\
& H_{V}\left\{\frac{Q \lambda}{P(1-E[\delta])}-\frac{N Q \lambda}{2 P(1-E[\delta])}+\frac{(N-1) Q}{2}\right\}+\frac{N T_{F} \lambda}{N Q(1-\mathrm{E}[\delta])}+\frac{T_{V} N Q E[\delta] \lambda}{N Q(1-\mathrm{E}[\delta])}+\frac{N C_{F} \lambda}{N Q(1-\mathrm{E}[\delta])}+ \\
& \frac{C_{V} \lambda E[\delta] N Q}{N Q(1-\mathrm{E}[\delta])}+\frac{W_{V} N Q E[\delta] \lambda}{N Q(1-\mathrm{E}[\delta])}
\end{aligned}
$$

\section{Optimality and Solution Procedure}

\subsection{Optimality}

To get the optimum values of the order quantity, backordering quantity and investment in setup, the necessary conditions to establish convexity are given as:

$$
\begin{aligned}
& \frac{\partial \mathrm{ETC}(N, Q, B, \xi)}{\partial Q}=0, \\
& \frac{\partial \mathrm{E} T C(N, Q, B, \xi)}{\partial B}=0, \\
& \frac{\partial \mathrm{E} T C(N, Q, B, \xi)}{\partial \xi}=0 .
\end{aligned}
$$

By using Eq. (17), Eq. (18) and Eq. (19), the values of $Q, B$, and $\xi$ are obtained as:

$$
\begin{aligned}
& Q^{*}(N)=\sqrt{\frac{\left(O_{B}+S_{0} e^{-k \xi}+\xi\right) \lambda}{N}+\frac{\left(H_{B}+C_{B}\right) B^{2}}{2}+\left(T_{F}+C_{F}\right) \lambda} \\
& B^{*}(N)=\frac{H_{B} Q^{*}(N)(1-E[\delta])}{\left(H_{B}+C_{B}\right)} \\
& \xi^{*}(n)=\frac{1}{k} \ln S_{0} k
\end{aligned}
$$

All the first order derivatives are calculated in Appendix A.

$N$ is a discrete variable thus to obtain the optimum value of $N$ a solution procedure is adopted which is discussed in subsequent section, the sufficient condition for rest of the variables is in the form of hessian matrix given below:

$$
\left[\begin{array}{lll}
\frac{\partial^{2} E T C(N, Q, B, \xi)}{\partial Q^{2}} & \frac{\partial^{2} E T C(N, Q, B, \xi)}{\partial Q \partial B} & \frac{\partial^{2} E T C(N, Q, B, \xi)}{\partial Q \partial \xi} \\
\frac{\partial^{2} E T C(N, Q, B, \xi)}{\partial B \partial Q} & \frac{\partial^{2} E T C(N, Q, B, \xi)}{\partial B^{2}} & \frac{\partial^{2} E T C(N, Q, B, \xi)}{\partial B \partial \xi} \\
\frac{\partial^{2} E T C(N, Q, B, \xi)}{\partial \xi \partial Q} & \frac{\partial^{2} E T C(N, Q, B, \xi)}{\partial \xi \partial B} & \frac{\partial^{2} E T C(N, Q, B, \xi)}{\partial \xi^{2}}
\end{array}\right]
$$




$$
\begin{aligned}
& D_{1}=\frac{\partial^{2} E T C(N, Q, B, \boldsymbol{\xi})}{\partial Q^{2}}, D_{2}=\left[\begin{array}{ll}
\frac{\partial^{2} E T C(N, Q, B, \xi)}{\partial Q^{2}} & \frac{\partial^{2} E T C(N, Q, B, \xi)}{\partial Q \partial B} \\
\frac{\partial^{2} E T C(N, Q, B, \xi)}{\partial B \partial Q} & \frac{\partial^{2} E T C(N, Q, B, \xi)}{\partial B^{2}}
\end{array}\right], \\
& D_{3}=\operatorname{det} H_{e}=\left[\begin{array}{lll}
\frac{\partial^{2} E T C(N, Q, B, \xi)}{\partial Q^{2}} & \frac{\partial^{2} E T C(N, Q, B, \xi)}{\partial Q \partial B} & \frac{\partial^{2} E T C(N, Q, B, \boldsymbol{\xi})}{\partial Q \partial \xi} \\
\frac{\partial^{2} E T C(N, Q, B, \xi)}{\partial B \partial Q} & \frac{\partial^{2} E T C(N, Q, B, \xi)}{\partial B^{2}} & \frac{\partial^{2} E T C(N, Q, B, \boldsymbol{\xi})}{\partial B \partial \xi} \\
\frac{\partial^{2} E T C(N, Q, B, \xi)}{\partial \xi \partial Q} & \frac{\partial^{2} E T C(N, Q, B, \xi)}{\partial \xi \partial B} & \frac{\partial^{2} E T C(N, Q, B, \xi)}{\partial \xi^{2}}
\end{array}\right], \text { where } D_{1}, D_{2} \text { and }
\end{aligned}
$$

$D_{3}$ are minors of the Hessian matrix.

All the second order derivatives and optimality conditions are calculated in Appendix B and C.

The second derivative of $N$ shows the joint total expected cost is a convex function of $N$. To obtain the optimum value of $N$ a solution procedure is adopted which is given below:

\subsection{Solution Procedure}

Step 1: Obtain the corresponding values of the optimal order size, backordering quantity and investment in setup from the Eq. (18), Eq. (19), and Eq. (20) for a set of $N$ values and calculate the total expected cost from Eq. (17).

Step 2: Obtain the optimum value of $N$ so that the condition given below is fulfilled:

$$
\begin{aligned}
& T C\left(N+1, Q^{*}(N+1), B^{*}(N+1), \xi^{*}(N+1)\right) \geq T C\left(N, Q^{*}(N), B^{*}(N), \xi^{*}(N)\right) \leq \\
& T C\left(N-1, Q^{*}(N-1), B^{*}(N-1), \xi^{*}(N-1)\right)
\end{aligned}
$$

Step 3: After finding the optimal value of the number of shipment the optimum production batch quantity is calculated as $Q_{\text {prod. }}=N^{*} Q^{*}\left(N^{*}\right)$

\subsection{The individual decision-making of buyer}

When the traditional approach of working independently is preferred over working in collaboration, the expected total annual buyer's cost is calculated as:

$$
\mathrm{ETC}_{B}(Q, B)=\frac{O_{B} \lambda}{Q(1-\mathrm{E}[\delta])}+\frac{S N \lambda}{(1-\mathrm{E}[\delta])}+H_{B}\left\{\begin{array}{l}
\frac{1}{2}\left(\frac{Q \mathrm{E}\left[(1-\delta)^{2}\right]}{(1-\mathrm{E}[\delta])}-2 B+\frac{B^{2}}{Q(1-\mathrm{E}[\delta])}\right)+ \\
\frac{Q\left(\mathrm{E}[\delta]-\mathrm{E}\left[\delta^{2}\right]\right)}{(1-\mathrm{E}[\delta])}
\end{array}\right\}+\frac{C_{B} B^{2}}{2 Q(1-\mathrm{E}[\delta])}
$$

and the optimum values are obtained as:

$$
Q_{B}^{*}=\sqrt{\frac{2 O_{B} \lambda+C_{B} B^{2}+H_{B} B^{2}}{H_{B} E\left[(1-\delta)^{2}\right]+2\left(E[\delta]-E\left[\delta^{2}\right]\right)}}
$$




$$
B_{B}^{*}=\frac{H_{B}(1-E[\delta]) Q_{B}^{*}}{\left(H_{B}+C_{B}\right)}
$$

The expected total annual cost of the buyer is:

$$
\begin{aligned}
& E T C_{V}(Q, \xi)=\frac{S_{0} \lambda e^{-k \xi}}{Q(1-E[\delta])}+\frac{\xi \lambda}{Q(1-E[\delta])}+\frac{H_{V} Q \lambda}{2 \psi(1-E[\delta])}+\frac{n \lambda T_{F}}{Q(1-E[\delta])}+\frac{T_{V} \lambda E[\delta]}{(1-E[\delta])}+ \\
& \frac{N \lambda C_{F}}{Q(1-E[\delta])}+\frac{C_{V} \lambda E[\delta]}{(1-E[\delta])}+\frac{W_{V} \lambda E[\delta]}{(1-E[\delta])}
\end{aligned}
$$

If the decision making depends on the buyer only, then by putting $Q=Q_{B}^{*}$ and $B=B_{B}^{*}$ in Eq. (24) and $Q=Q_{B}^{*}$ in Eq. (27), correspondingly the expected total annual costs of the vendor and buyer is obtained.

\section{Numerical Analysis}

Example: The value of the parameters are taken as: $\psi=160000$ units/year, $\lambda=50000$ units/year, $O_{B}=\$ 300$ /order, $T_{F}=25 /$ delivery, $T_{V}=0.1 /$ unit, $C_{F}=\$ 5 /$ delivery, $C_{V}=\$ 5 /$ unit, $C_{B}=\$ 10$ /unit/year, $S=\$ 0.5 /$ unit, $H_{B}=\$ 5 /$ unit/year, $H_{V}=\$ 2 /$ unit, $W_{V}=\$ 30 /$ unit, $\beta=0.04, S_{0}=\$ 1000$ /setup, $k=0.00140$ by making use of the numerical data from Sarkar et al. (2016) and Hsu and Hsu (2012).

The following results are obtained: $N^{*}=9, Q^{*}=1073.43$ units, $B^{*}=350.65$ units, $\xi^{*}=\$ 240.33$ per production run, and the total expected integrated cost $=\$ 77325.83$.

The buyer's independent decision making policy leads to $Q^{*}=2971.89$ units, $B^{*}=970.82$ units, total cost of the buyer is $\$ 35810.77$, total cost of vendor is $\$ 43717.02$, and the reduction of cost through integrated model is $\$ 35810.77+\$ 43717.02$ - $\$ 77325.83=\$ 2201.96$.

\section{Sensitivity Analysis}

In the present section, the proposed model is tested for its robustness by changing the model parameters. Table 1 presents the model sensitivity with respect to buyer and vendor holding costs, defective fraction, fixed and variable parts of shipments and carbon-emissions. Table 2 presents the sensitivity with respect to setup cost reduction parameter.

\section{Table 1}

The model sensitivity with respect to buyer and vendor holding costs, defective fraction, fixed and variable parts of shipments and carbon-emissions

\begin{tabular}{cccccccccc}
\hline $\boldsymbol{H}_{\boldsymbol{B}}$ & $\boldsymbol{Q}_{\boldsymbol{B}}^{*}$ & $\boldsymbol{B}_{\boldsymbol{B}}^{*}$ & Buyer's Cost & Vendor's Cost & $\boldsymbol{N}$ & $\boldsymbol{Q}^{*}(\boldsymbol{N})$ & $\boldsymbol{B}^{*}(\boldsymbol{N})$ & Integrated Cost & Reduction \\
\hline 2.5 & 3855.22 & 755.62 & 33450.66 & 43717.02 & 6 & 1601.84 & 313.95 & 76453.84 & 713.84 \\
\hline 3.75 & 3293.45 & 880.25 & 34805.06 & 43717.02 & 8 & 1211.17 & 323.71 & 76962.55 & 1559.53 \\
5.00 & 2971.90 & 970.82 & 35810.77 & 43717.02 & 9 & 1073.43 & 350.65 & 77325.83 & 2201.96 \\
\hline 6.25 & 2760.08 & 1040.33 & 36601.27 & 43717.02 & 10 & 968.38 & 365.00 & 77603.91 & 2714.38 \\
7.50 & 2608.49 & 1095.56 & 37245.79 & 43717.02 & 11 & 885.2 & 371.78 & 77828.28 & 3134.53 \\
\hline $\boldsymbol{\beta}$ & & & & & & & & & \\
\hline 0.02 & 2985.47 & 985.2 & 35402.66 & 25625.43 & 9 & 1068.75 & 352.68 & 58964.64 & 2063.45 \\
\hline 0.03 & 2978.57 & 977.96 & 35606.02 & 34631.78 & 9 & 1071.07 & 351.67 & 68105.26 & 2132.54 \\
0.04 & 2971.89 & 970.81 & 35810.77 & 43717.02 & 9 & 1073.43 & 350.65 & 77325.83 & 2201.96 \\
\hline 0.05 & 2965.45 & 963.77 & 36016.93 & 52882.36 & 9 & 1075.82 & 349.64 & 86627.60 & 2271.69 \\
0.06 & 2959.22 & 956.81 & 36224.54 & 62129.05 & 9 & 1078.24 & 348.63 & 96011.79 & 2341.80 \\
\hline
\end{tabular}




\begin{tabular}{|c|c|c|c|c|c|c|c|c|c|}
\hline $\boldsymbol{H}_{V}$ & & & & & & & & & \\
\hline 1.0 & 2971.89 & 970.81 & 35810.77 & 41372.47 & 14 & 982.69 & 321.01 & 73643.14 & 3540.10 \\
\hline 1.5 & 2971.89 & 970.81 & 35810.77 & 42644.58 & 11 & 1018.83 & 332.81 & 75650.33 & 2805.02 \\
\hline 2.0 & 2971.89 & 970.81 & 35810.77 & 43717.02 & 9 & 1073.43 & 350.65 & 77325.83 & 2201.96 \\
\hline 2.5 & 2971.89 & 970.81 & 35810.77 & 44661.85 & 8 & 1085.37 & 354.55 & 78786.91 & 1685.71 \\
\hline 3.0 & 2971.89 & 970.81 & 35810.77 & 45516.05 & 7 & 1131.26 & 369.54 & 80095.22 & 1231.60 \\
\hline \multicolumn{10}{|l|}{$T_{F}$} \\
\hline 12.50 & 2971.9 & 970.82 & 35810.77 & 43666.04 & 12 & 807.74 & 263.86 & 76641.03 & 2835.80 \\
\hline 18.75 & 2971.9 & 970.82 & 35810.77 & 43691.57 & 10 & 964.59 & 315.10 & 77007.04 & 2495.30 \\
\hline 25.00 & 2971.9 & 970.82 & 35810.77 & 43717.02 & 9 & 1073.43 & 350.65 & 77325.83 & 2202.00 \\
\hline 31.25 & 2971.9 & 970.82 & 35810.77 & 43742.38 & 8 & 1201.86 & 392.60 & 77615.20 & 1938.00 \\
\hline 37.50 & 2971.9 & 970.82 & 35810.77 & 43767.67 & 8 & 1221.16 & 398.91 & 77878.40 & 1700.00 \\
\hline \multicolumn{10}{|l|}{$C_{F}$} \\
\hline 2.50 & 2971.89 & 970.81 & 35810.77 & 43706.85 & 10 & 976.64 & 319.03 & 77204.16 & 2313.46 \\
\hline 3.75 & 2971.89 & 970.81 & 35810.77 & 43711.93 & 9 & 1069.46 & 349.35 & 77266.31 & 2256.39 \\
\hline 5.00 & 2971.89 & 970.81 & 35810.77 & 43717.02 & 9 & 1073.43 & 350.65 & 77325.83 & 2201.96 \\
\hline 6.25 & 2971.89 & 970.81 & 35810.77 & 43722.1 & 9 & 1077.38 & 351.94 & 77385.14 & 2147.73 \\
\hline 7.50 & 2971.89 & 970.81 & 35810.77 & 43727.17 & 9 & 1081.32 & 353.23 & 77444.22 & 2093.72 \\
\hline \multicolumn{10}{|l|}{$T_{V}$} \\
\hline 0.050 & 2971.89 & 970.81 & 35810.77 & 43667.02 & 9 & 1073.43 & 350.65 & 77275.80 & 2201.96 \\
\hline 0.075 & 2971.89 & 970.81 & 35810.77 & 43692.02 & 9 & 1073.43 & 350.65 & 77300.80 & 2201.96 \\
\hline 0.100 & 2971.89 & 970.81 & 35810.77 & 43717.02 & 9 & 1073.43 & 350.65 & 77325.83 & 2201.96 \\
\hline 0.125 & 2971.89 & 970.81 & 35810.77 & 43742.02 & 9 & 1073.43 & 350.65 & 77350.80 & 2201.96 \\
\hline 0.250 & 2971.89 & 970.81 & 35810.77 & 43867.02 & 9 & 1073.43 & 350.65 & 77475.80 & 2201.96 \\
\hline \multicolumn{10}{|l|}{$C_{V}$} \\
\hline 2.50 & 2971.89 & 970.81 & 35810.77 & 41217.02 & 9 & 1073.43 & 350.65 & 74825.83 & 2201.96 \\
\hline 3.75 & 2971.89 & 970.81 & 35810.77 & 42467.02 & 9 & 1073.43 & 350.65 & 76075.83 & 2201.96 \\
\hline 5.00 & 2971.89 & 970.81 & 35810.77 & 43717.02 & 9 & 1073.43 & 350.65 & 77325.83 & 2201.96 \\
\hline 6.25 & 2971.89 & 970.81 & 35810.77 & 44967.02 & 9 & 1073.43 & 350.65 & 78575.83 & 2201.96 \\
\hline 7.50 & 2971.89 & 970.81 & 35810.77 & 46217.02 & 9 & 1073.43 & 350.65 & 79825.83 & 2201.96 \\
\hline
\end{tabular}

Table 2

The sensitivity with respect to setup cost reduction parameter

\begin{tabular}{ccccccccccc}
\hline $\boldsymbol{k}$ & $\boldsymbol{Q}_{\boldsymbol{B}}^{*}$ & $\boldsymbol{B}_{\boldsymbol{B}}^{*}$ & Buyer's Cost & Vendor's Cost & $\boldsymbol{N}$ & $\boldsymbol{Q}^{*}(\boldsymbol{N})$ & $\boldsymbol{B}^{*}(\boldsymbol{N})$ & $\boldsymbol{\xi}$ & Integrated Cost & Reduction \\
\hline 0.0007 & 2971.89 & 970.81 & 35810.77 & 43899.39 & 9 & 1089.29 & 355.83 & 0 & 77563.70 & 2146.4 \\
0.0010 & 2971.89 & 970.81 & 35810.77 & 43899.39 & 9 & 1089.29 & 355.83 & 0 & 77563.70 & 2146.5 \\
0.0014 & 2971.89 & 970.81 & 35810.77 & 43717.02 & 9 & 1073.43 & 350.65 & 240.33 & 77325.83 & 2202.0 \\
0.0017 & 2971.89 & 970.81 & 35810.77 & 43493.36 & 9 & 1054.16 & 344.35 & 312.13 & 77036.70 & 2267.4 \\
0.0021 & 2971.89 & 970.81 & 35810.77 & 43191.10 & 9 & 1028.44 & 335.95 & 353.30 & 76650.90 & 2351.0 \\
\hline
\end{tabular}

\subsection{Observations and Managerial Implications}

The effective management of any production firm requires proper care of its inventory. In the present scenario (see Table 1), as the inventory carrying cost of buyer raises, the total cost of the system increases, the order size decreases, and backorders increases. With the advent of increase in holding cost, the wise decision would be to backorder the demand to the hilt so as to avoid the incurrence of higher holding costs. However, with an increase in the vendor's holding cost the total cost of the inventory system along with the order quantity rises and shipment frequency decreases which is fairly reasonable because the shipment of the items is done in bulk in an attempt to avoid the vendor's high holding cost.

The presence of defective items in the inventory system requires vigilant decision to pacify its effect. Here, with an increase in the defective percentage $\delta$, which is assumed to be distributed uniformly over 
0 and $\beta$, the economic order quantity rises so as to satisfy the end demand and the total cost rises as the items are vended at a reduced price which was supposed to be sold at the original price. The increasing number of defectives suggests that the vendor should adopt better investment policies in setup so as to avoid incurrence of loss due defectives.

The proposed model assumes that the shipments are done between vendor and buyer and this incurs a cost of carbon-emissions at the vendor. So, in this case with increasing fixed cost of transportation, the total cost and shipment quantity is increasing and the frequency of the shipments is decreasing which is fairly logical as the vendor will deliver larger quantities to the buyer so as to avoid frequent shipments and thereby prevents high transportation costs. Also, the rise in variable transportation cost implies arise in total costs of the inventory system. This cost is incurred by the vendor thereby the vendor's cost also increases. And, when the fixed cost of carbon-emissions increases the frequency of shipments is decreased so as to avoid large emissions while transporting the goods between vendor and buyer and the total cost will increase. The cost at the vendor is increasing because the cost of carbon-emissions is adhered by the vendor, however, the cost of buyer remains intact. It has been further noticed that as the variable cost of carbon emissions raises the total cost of inventory system rises along with the total cost of vendor. The cost of buyer remains insensitive to the change in the carbon-emissions costs. Furthermore, with an increase in the value of $k$ (see Table 2), it is seen that the total cost of the inventory system is declining, however, the investment cost is increasing. The increasing value of $k$ is beneficial for the organization. With the increase in the investment cost there is a significant decrease in the total cost, hence, investment in setup cost is recommended.

\section{Concluding Remarks}

\subsection{Conclusion}

In this paper, the problem of two players' viz. vendor and buyer has been formulated under integrated as well as individual environments. At vendor's end, the manufacturing process was presumed to be faulty and henceforward items of imperfect quality were manufactured. Serving the end customers with goods of expected standards and quality was the ultimate motto of any efficient supply chain system. Thus, the imperfect items were screened by the buyer and returned to the vendor and this incurs a warranty cost. The vendor makes a one-time discrete investment in setup costs so as to reduce the overall cost of production for the upcoming cycles. In order to control imperfect quality items, the investment in the setup process is beneficial as it helps in achieving an efficient production process that will ultimately assist in monitoring the production of defectives. The vendor administers the transportation process. The prominence of transportation from an emission viewpoint is apparent. Thus, while transporting the goods, fixed and variable cost components of carbon-emissions are considered so as to attain sustainability. The findings give cost reduction in case of the integrated model and suggest better performance of the integrated model over independent model which supports the notion of working in collaboration. Further, investment in setup process aids in minimizing the overall cost of the system which makes the present model quite applicable to real-time inventory scenarios. The model is validated with numerical analysis. Further, a comprehensive sensitivity analysis is incorporated which imparts the vital characteristics of the model. The present model caters an interesting contribution towards managing integrated supply chain and production related problems. Various production firms like plastic, leather, footwear etc. will be benefited with an enhanced approach of decision-making.

\subsection{Directions for Future Research}

The present model is extensively applicable to numerous production firms and to scenarios in which a vendor and a buyer are associated, however, this could have been more pragmatic by taking into account partial backordering, price discounts to encourage backorders, inspection errors etc. The study 
can be extended further for the case of multi-buyers and multi-item under green supply chain. Finally, a good contribution would be made by considering the supply disruptions.

\section{References}

Aderohunmu, R., Mobolurin, A., \& Bryson, N. (1995). Joint vendor-buyer policy in JIT manufacturing. Journal of the Operational Research Society, 375-385.

Annadurai, K., \& Uthayakumar, R. (2010). Controlling setup cost in (Q, r, L) inventory model with defective items. Applied Mathematical Modelling, 34(6), 1418-1427.

Banerjee, A. (1986). A joint economic lot size model for purchaser and vendor. Decision sciences, 17(3), 292-311.

Ben-Daya, M., \& Hariga, M. (2000). Economic lot scheduling problem with imperfect production processes. Journal of the Operational Research Society, 51(7), 875-881.

Ben-Daya, M., \& Rahim, A. (2003). Optimal lot-sizing, quality improvement and inspection errors for multistage production systems. International Journal of Production Research, 41(1), 65-79.

Cárdenas-Barrón, L. E. (2000). Observation on:"Economic production quantity model for items with imperfect quality"'Int. J. Production Economics 64 (2000) 59-64]. International Journal of Production Economics, 67(2), 201.

Cárdenas-Barrón, L. E. (2009). Economic production quantity with rework process at a single-stage manufacturing system with planned backorders. Computers \& Industrial Engineering, 57(3), 1105 1113.

Chang, H. C., \& Ho, C. H. (2010). Exact closed-form solutions for "optimal inventory model for items with imperfect quality and shortage backordering". Omega, 38(3), 233-237.

Chen, C. K., \& Lo, C. C. (2006). Optimal production run length for products sold with warranty in an imperfect production system with allowable shortages. Mathematical and Computer Modelling, 44(3), 319-331.

Cheng, C., Qi, M., Wang, X., \& Zhang, Y. (2016). Multi-period inventory routing problem under carbon emission regulations. International Journal of Production Economics, 182, 263-275.

Chung, K. J. (2008). An improvement of an integrated single-vendor single-buyer inventory model with shortage. Production Planning and Control, 19(3), 275-277.

Chung, K. J., \& Hou, K. L. (2003). An optimal production run time with imperfect production processes and allowable shortages. Computers \& Operations Research, 30(4), 483-490.

Denizel, M., Erengüç, S., \& Benson, H. P. (1997). Dynamic lot-sizing with setup cost reduction. European Journal of Operational Research, 100(3), 537-549.

Diaby, M. (2000). Integrated batch size and setup reduction decisions in multi-product, dynamic manufacturing environments. International Journal of Production Economics, 67(3), 219-233.

Eroglu, A., \& Ozdemir, G. (2007). An economic order quantity model with defective items and shortages. International journal of production economics, 106(2), 544-549.

Freimer, M., Thomas, D., \& Tyworth, J. (2006). The value of setup cost reduction and process improvement for the economic production quantity model with defects. European Journal of Operational Research, 173(1), 241-251.

Goyal, S. K. (1977). An integrated inventory model for a single supplier-single customer problem. The International Journal of Production Research, 15(1), 107-111.

Goyal, S. K. (1988). "A JOINT ECONOMIC-LOT-SIZE MODEL FOR PURCHASER AND VENDOR”: A COMMENT. Decision sciences, 19(1), 236-241.

Goyal, S. K., \& Gupta, Y. P. (1989). Integrated inventory models: the buyer-vendor coordination. European journal of operational research, 41(3), 261-269.

Goyal, S. K., \& Nebebe, F. (2000). Determination of economic production-shipment policy for a single-vendor-single-buyer system. European Journal of Operational Research, 121(1), 175-178.

Goyal, S. K., \& Szendrovits, A. Z. (1986). A constant lot size model with equal and unequal sized batch shipments between production stages. Engineering Costs and Production Economics, 10(1), 203210. 
Goyal, S. K., Huang, C. K., \& Chen, K. C. (2003). A simple integrated production policy of an imperfect item for vendor and buyer. Production Planning \& Control, 14(7), 596-602.

Ha, D., \& Kim, S. L. (1997). Implementation of JIT purchasing: an integrated approach. Production Planning \& Control, 8(2), 152-157.

Hammami, R., Nouira, I., \& Frein, Y. (2015). Carbon emissions in a multi-echelon productioninventory model with lead time constraints. International Journal of Production Economics, 164, 292-307.

Hill, R. M. (1997). The single-vendor single-buyer integrated production-inventory model with a generalised policy. European journal of operational research, 97(3), 493-499.

Hill, R. M. (1999). The optimal production and shipment policy for the single-vendor singlebuyer integrated production-inventory problem. International Journal of Production Research, 37(11), 2463-2475.

Hoque, M. A., \& Goyal, S. K. (2000). An optimal policy for a single-vendor single-buyer integrated production-inventory system with capacity constraint of the transport equipment. International Journal of Production Economics, 65(3), 305-315.

Hsieh, C. C., \& Lee, Z. Z. (2005). Joint determination of production run length and number of standbys in a deteriorating production process. European Journal of Operational Research, 162(2), 359-371.

Hsu, J., \& Hsu, L. (2012). An integrated single-vendor single-buyer production-inventory model for items with imperfect quality and inspection errors. International Journal of Industrial Engineering Computations, 3(5), 703-720.

Hsu, J. T., \& Hsu, L. F. (2013). An integrated vendor-buyer cooperative inventory model in an imperfect production process with shortage backordering. The International Journal of Advanced Manufacturing Technology, 1-13.

Huang, C. K. (2002). An integrated vendor-buyer cooperative inventory model for items with imperfect quality. Production Planning \& Control, 13(4), 355-361.

Huang, C. K. (2004). An optimal policy for a single-vendor single-buyer integrated productioninventory problem with process unreliability consideration. International Journal of Production Economics, 91(1), 91-98.

Huang, C. K., Cheng, T. L., Kao, T. C., \& Goyal, S. K. (2011). An integrated inventory model involving manufacturing setup cost reduction in compound Poisson process. International Journal of Production Research, 49(4), 1219-1228.

Khanna, A., Gautam, P., \& Jaggi, C. K. (2016, March). Coordinating vendor-buyer decisions for imperfect quality items considering trade credit and fully backlogged shortages. In AIP Conference Proceedings (Vol. 1715, No. 1, p. 020065). AIP Publishing.

Khanna, A., Mittal, M., Gautam, P., \& Jaggi, C. (2016). Credit financing for deteriorating imperfect quality items with allowable shortages. Decision Science Letters, 5(1), 45-60.

Kim, C. H., \& Hong, Y. (1999). An optimal production run length in deteriorating production processes. International Journal of Production Economics, 58(2), 183-189.

Lee, H. L., \& Rosenblatt, M. J. (1987). Simultaneous determination of production cycle and inspection schedules in a production system. Management science, 33(9), 1125-1136.

Lu, L. (1995). A one-vendor multi-buyer integrated inventory model. European Journal of Operational Research, 81(2), 312-323.

Nye, T. J., Jewkes, E. M., \& Dilts, D. M. (2001). Optimal investment in setup reduction in manufacturing systems with WIP inventories. European Journal of Operational Research, 135(1), 128-141.

Porteus, E. L. (1986). Optimal lot sizing, process quality improvement and setup cost reduction. Operations research, 34(1), 137-144.

Rosenblatt, M. J., \& Lee, H. L. (1986). Economic production cycles with imperfect production processes. IIE transactions, 18(1), 48-55.

Salameh, M. K., \& Jaber, M. Y. (2000). Economic production quantity model for items with imperfect quality. International journal of production economics, 64(1), 59-64. 
Sana, S. S. (2011). A production-inventory model of imperfect quality products in a three-layer supply chain. Decision Support Systems, 50(2), 539-547.

Sarkar, B., \& Majumder, A. (2013). Integrated vendor-buyer supply chain model with vendor's setup cost reduction. Applied Mathematics and Computation, 224, 362-371.

Sarkar, B., \& Moon, I. (2014). Improved quality, setup cost reduction, and variable backorder costs in an imperfect production process. International journal of production economics, 155, 204-213.

Sarkar, B., Chaudhuri, K., \& Moon, I. (2015). Manufacturing setup cost reduction and quality improvement for the distribution free continuous-review inventory model with a service level constraint. Journal of Manufacturing Systems, 34, 74-82.

Sarkar, B., Ganguly, B., Sarkar, M., \& Pareek, S. (2016). Effect of variable transportation and carbon emission in a three-echelon supply chain model. Transportation Research Part E: Logistics and Transportation Review, 91, 112-128.

Sarkar, B., Saren, S., Sarkar, M., \& Seo, Y. W. (2016). A Stackelberg Game Approach in an Integrated Inventory Model with Carbon-Emission and Setup Cost Reduction. Sustainability, 8(12), 1244.

Shah, N., \& Shah, D. (2012). Vendor-buyer ordering policy when demand is trapezoidal. International Journal of Industrial Engineering Computations, 3(5), 721-730.

Shi, X., \& Meier, H. (2012). Carbon emission assessment to support planning and operation of lowcarbon production systems. Procedia CIRP, 3, 329-334.

Shi, Y., Chen, L., Liu, Z., Yan, J., \& Hu, J. (2012). Analysis on the carbon emission reduction potential in the cement industry in terms of technology diffusion and structural adjustment: a case study of Chongqing. Energy Procedia, 16, 121-130.

Tang, J., Ji, S., \& Jiang, L. (2016). The design of a sustainable location-routing-inventory model considering consumer environmental behavior. Sustainability, 8(3), 211.

Tang, S., Wang, W., Yan, H., \& Hao, G. (2015). Low carbon logistics: Reducing shipment frequency to cut carbon emissions. International Journal of Production Economics, 164, 339-350.

Viswanathan, S. (1998). Optimal strategy for the integrated vendor-buyer inventory model. European Journal of Operational Research, 105(1), 38-42.

Wee, H. M., Yu, J., \& Chen, M. C. (2007). Optimal inventory model for items with imperfect quality and shortage backordering. Omega, 35(1), 7-11.

Wu, K. S., \& Ouyang, L. Y. (2003). An integrated single-vendor single-buyer inventory system with shortage derived algebraically. Production Planning \& Control, 14(6), 555-561.

Yang, P. C., \& Wee, H. M. (2000). Economic ordering policy of deteriorated item for vendor and buyer: an integrated approach. Production Planning \& Control, 11(5), 474-480.

Yeh, R. H., Ho, W. T., \& Tseng, S. T. (2000). Optimal production run length for products sold with warranty. European Journal of Operational Research, 120(3), 575-582.

Zhang, X., Liu, P., Li, Z., \& Yu, H. (2013). Modeling the effects of low-carbon emission constraints on mode and route choices in transportation networks. Procedia-Social and Behavioral Sciences, 96, 329-338.

\section{Appendix A}

$$
\begin{aligned}
& \frac{\partial \mathrm{E} T C(n, Q, B, \xi)}{\partial Q}=-\frac{O_{B} D}{n Q^{2}(1-\mathrm{E}[\delta])}-\frac{S_{0} D e^{-k \xi}}{n Q^{2}(1-\mathrm{E}[\delta])}-\frac{\xi D}{n Q^{2}(1-\mathrm{E}[\delta])}-\frac{H_{B} B^{2}}{2 Q^{2}(1-\mathrm{E}[\delta])}+\frac{\left(\mathrm{E}[\delta]-\mathrm{E}\left[\delta^{2}\right]\right)}{(1-\mathrm{E}[\delta])}- \\
& \frac{C_{B} B^{2}}{2 Q^{2}(1-\mathrm{E}[\delta])}+\frac{H_{V} D}{P(1-\mathrm{E}[\delta])}-\frac{H_{V} n D}{2 P(1-\mathrm{E}[\delta])}+\frac{H_{V}(n-1)}{2}-\frac{T_{F} D}{Q^{2}(1-\mathrm{E}[\delta])}-\frac{C_{F} D}{Q^{2}(1-\mathrm{E}[\delta])} \\
& \frac{\partial \mathrm{E} T C(n, Q, B, \xi)}{\partial B}=-H_{B}+\frac{H_{B} B}{Q(1-\mathrm{E}[\delta])}+\frac{C_{B} B}{Q(1-\mathrm{E}[\delta])}
\end{aligned}
$$




$$
\begin{aligned}
& \frac{\partial \mathrm{E} T C(n, Q, B, \xi)}{\partial \xi}=\frac{D}{n Q(1-\mathrm{E}[\delta])}\left[S_{0} e^{-k \delta}+1\right] \\
& \frac{\partial \mathrm{E} T C(n, Q, B, \xi)}{\partial n}=-\frac{O_{B} D}{n^{2} Q(1-\mathrm{E}[\delta])}-\frac{S_{0} D e^{-k \xi}}{n^{2} Q(1-\mathrm{E}[\delta])}-\frac{\xi D}{n^{2} Q(1-\mathrm{E}[\delta])}+H_{V}\left\{-\frac{Q D}{2 P(1-E[\delta])}+\frac{Q}{2}\right\}
\end{aligned}
$$

\section{Appendix B}

$$
\begin{aligned}
& \frac{\partial^{2} \mathrm{E} T C(n, Q, B, \xi)}{\partial Q^{2}}=\frac{2 O_{B} D}{n Q^{3}(1-\mathrm{E}[\delta])}+\frac{2 S_{0} D e^{-k \xi}}{n Q^{3}(1-\mathrm{E}[\delta])}+\frac{2 \xi D}{n Q^{3}(1-\mathrm{E}[\delta])}+\frac{H_{B} B^{2}}{Q^{3}(1-\mathrm{E}[\delta])}+ \\
& \frac{C_{B} B^{2}}{Q^{3}(1-\mathrm{E}[\delta])}+\frac{2 T_{F} D}{Q^{3}(1-\mathrm{E}[\delta])}+\frac{2 C_{F} D}{Q^{3}(1-\mathrm{E}[\delta])} \\
& \frac{\partial^{2} \mathrm{E} T C(n, Q, B, \xi)}{\partial B^{2}}=\frac{H_{B}+C_{B}}{Q(1-\mathrm{E}[\delta])} \\
& \frac{\partial^{2} \mathrm{E} T C(n, Q, B, \xi)}{\partial \xi^{2}}=\frac{D S_{0} k^{2} e^{-k \delta}}{n Q(1-\mathrm{E}[\delta])} \\
& \frac{\partial^{2} \mathrm{E} T C(n, Q, B, \xi)}{\partial n^{2}}=\frac{2 O_{B} D}{n^{3} Q(1-\mathrm{E}[\delta])}+\frac{2 S_{0} D e^{-k \xi}}{n^{3} Q(1-\mathrm{E}[\delta])}+\frac{2 \xi D}{n^{3} Q(1-\mathrm{E}[\delta])} \\
& \frac{\partial E T C(n, Q, B, \xi)}{\partial Q \partial \xi}=\frac{D}{n Q^{2}(1-E[\delta])}\left[S_{0} k e^{-k \xi}-1\right] \\
& \frac{\partial E T C(n, Q, B, \xi)}{\partial Q \partial B}=\frac{-B\left(H_{B}+C_{B}\right)}{Q^{2}(1-E[\delta])} \\
& \frac{\partial E T C(n, Q, B, \xi)}{\partial B \partial Q}=\frac{-B\left(H_{B}+C_{B}\right)}{Q^{2}(1-E[\delta])} \\
& \frac{\partial E T C(n, Q, B, \xi)}{\partial B \partial \xi}=0 \\
& \frac{\partial E T C(n, Q, B, \xi)}{\partial \xi \partial Q}=\frac{D}{n Q^{2}(1-E[\delta])}\left[S_{0} k e^{-k \xi}-1\right] \\
& \frac{\partial E T C(n, Q, B, \xi)}{\partial \xi \partial B}=0
\end{aligned}
$$

\section{APPENDIX C}

$$
D_{1}=\frac{\partial^{2} \mathrm{E} T C(n, Q, B, \xi)}{\partial Q^{2}}=\left(\begin{array}{l}
\frac{2 O_{B} D}{n Q^{3}(1-\mathrm{E}[\delta])}+\frac{2 S_{0} D e^{-k \xi}}{n Q^{3}(1-\mathrm{E}[\delta])}+\frac{2 \xi D}{n Q^{3}(1-\mathrm{E}[\delta])}+\frac{H_{B} B^{2}}{Q^{3}(1-\mathrm{E}[\delta])}+ \\
\frac{C_{B} B^{2}}{Q^{3}(1-\mathrm{E}[\delta])}+\frac{2 T_{F} D}{Q^{3}(1-\mathrm{E}[\delta])}+\frac{2 C_{F} D}{Q^{3}(1-\mathrm{E}[\delta])}
\end{array}\right)>0
$$


$D_{2}=\left(\frac{\partial^{2} \mathrm{E} T C(n, Q, B, \xi)}{\partial Q^{2}} * \frac{\partial^{2} \mathrm{E} T C(n, Q, B, \xi)}{\partial B^{2}}\right)-\left(\frac{\partial E T C(n, Q, B, \xi)}{\partial Q \partial B}\right)^{2}$

$$
\begin{aligned}
& =\left(\left(\left[\begin{array}{l}
\frac{2 O_{B} D}{n Q^{3}(1-\mathrm{E}[\delta])}+\frac{2 S_{0} D e^{-k \xi}}{n Q^{3}(1-\mathrm{E}[\delta])}+\frac{2 \xi D}{n Q^{3}(1-\mathrm{E}[\delta])}+\frac{H_{B} B^{2}}{Q^{3}(1-\mathrm{E}[\delta])}+ \\
= \\
\frac{C_{B} B^{2}}{Q^{3}(1-\mathrm{E}[\delta])}+\frac{2 T_{F} D}{Q^{3}(1-\mathrm{E}[\delta])}+\frac{2 C_{F} D}{Q^{3}(1-\mathrm{E}[\delta])} \\
\left(\left[\frac{-B\left(H_{B}+C_{B}\right)}{Q^{2}(1-\mathrm{E}[\delta])}\right]^{2}\right)
\end{array}\right)\right.\right. \\
& D_{3}=\left(A_{1}-A_{2}-A_{3}\right)>0
\end{aligned}
$$

where,

$$
\begin{aligned}
& A_{1}=\left(\begin{array}{l}
{\left[\begin{array}{l}
\frac{2 O_{B} D}{n Q^{3}(1-E[\delta])}+\frac{2 S_{D} D e^{-k \xi}}{n Q^{3}(1-E[\delta])}+\frac{2 \xi D}{n Q^{3}(1-E[\delta])}+\frac{H_{B} B^{2}}{Q^{3}(1-E[\delta])}+\frac{C_{B} B^{2}}{Q^{3}(1-E[\delta])} \\
\frac{2 T_{F} D}{Q^{3}(1-E[\delta])}+\frac{2 C_{F} D}{Q^{3}(1-E[\delta])} \\
{\left[\frac{H_{B}+C_{B}}{Q(1-E[\delta])}\right]^{2} *\left[\frac{D S_{0} k^{2} e^{-k \delta}}{n Q(1-E[\delta])}\right.}
\end{array}\right]^{2}}
\end{array}\right) \\
& \left.A_{2}=\left(\frac{-B\left(H_{B}+C_{B}\right)}{Q^{2}(1-E[\delta])} * \frac{D S_{0} k^{2} e^{-k \delta}}{n Q(1-E[\delta])}\right]^{2} * \frac{-B\left(H_{B}+C_{B}\right)}{Q^{2}(1-E[\delta])}\right) \\
& A_{3}=\left(\left[\frac{D}{n Q^{2}(1-E[\delta])}\left[S_{0} k e^{-k \xi}-1\right]\right] *\left[\frac{H_{B}+C_{B}}{Q(1-E[\delta])}\right]^{2} *\left(\frac{D}{n Q^{2}(1-E[\delta])}\left[S_{0} k e^{-k \xi}-1\right]\right)\right)
\end{aligned}
$$

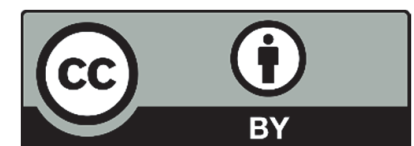

(C) 2018 by the authors; licensee Growing Science, Canada. This is an open access article distributed under the terms and conditions of the Creative Commons Attribution (CC-BY) license (http://creativecommons.org/licenses/by/4.0/). 